\title{
Formulation and evaluation of orally disintegrating tablet containing taste masked mirtazapine
}

\begin{abstract}
Objective: This study aims to prepare the taste-masked granules of Mirtazapine by mass extrusion technique and formulate it into an oral dispersible tablet using different super disintegrates.

Methods: Taste masked granules of mirtazapine were prepared by mass extrusion technique using Eudragit EPO in different ratios. The drug-polymer ratio was optimized based on the percent drug release in SSF and SGF. Taste masking efficacy of drug-polymer complex was determined by developing the bitterness threshold value of Mirtazapine. The selected drug-polymer complex was formulated into an oro-dispersible tablet by direct compression method. A randomized design was used to investigate individual effect of three different super disintegrates each in different concentrations. Ten formulations were developed including a controlled formulation without the addition of superdisintegrants. A comparative study was done based on various pre-compression and post-compression parameters.
\end{abstract}

Results: Eudragit EPO was able to mask the bitter taste of Mirtazapine effectively in 1:2 ratio by mass extrusion method. The minimum disintegration time and wetting time was found to be $13.6 \pm 2.7$ and $18.13 \pm 0.24$ seconds with the formulation containing crospovidone $5 \%$ (F9). It was found that the wetting time and disintegration time followed the order $\mathrm{SSG}>\mathrm{CCS}>\mathrm{CPV}$. The selected best formulation was subjected to an incompatibility study design. The IR spectrum showed that all the excipients were chemically compatible.

Conclusion: Thus, in this study unpalatable taste of Mirtazapine was masked using Eudragit EPO polymer by mass extrusion technique, and superdisintegrants were added to prepare orally disintegrating tablets of Mirtazapine. This research work suggests a rapid, simple and cost effective method for formulating Mirtazapine ODT.

Keywords: oral disintegrating tablet, formulation, complexation, mass extrusion, oral drug delivery, polymer, dissolution
Volume 10 Issue 2 - 202I

\author{
Shrestha Prabhat, Shrestha Rajan, Shrestha \\ Sahana \\ Department of Pharmacy, Kathmandu University, Nepal
}

Correspondence: Shrestha Prabhat, Department of Pharmacy, Kathmandu University, Dhulikhel, Kavrepalanchok, Nepal, Email prabhatshresthal@gmail.com

Received: March II, 202I | Published: March 29, 202

\section{Introduction}

One of the major properties governing the patient compliance of the drug is its taste. ${ }^{1}$ Oral administration of the bitter drug with an acceptable degree of palatability is a key issue for health care providers. To achieve better compliance and therapeutic value for the patient and more business and profits for the company main practical problem that confronts a pharmacist is to mask the unpleasant taste of the drug. ${ }^{2}$ Major taste-masking efforts are required before acceptance of the drug for marketing. It is important at this point to introduce some basic concepts related to the taste masking of the drug. The basic concept behind the taste masking of any drug is based on the reduction of its solubility in the saliva so that the drug concentration in the saliva will be lower than that of the threshold value. The desire for improved palatability of formulations led to the development of various new technologies for taste abatement. Many of these technologies were successfully commercialized. ${ }^{3}$ Comforts of drug administration and patient compliance turned out to be an important consideration for the design of dosage forms. Many technologies were developed for the manufacturing of robust and versatile tablets with taste-masking and controlling release pattern. One such approach is the Oro-dispersible tablet. ODT's offers a great advantage for patients having difficulty in swallowing (dysphasia). ${ }^{4}$ ODTs are solid dosage forms that rapidly disintegrate in the mouth and are thus swallowed without the need for water. In recent days ODTs technology that makes tablets dissolve or disintegrate in the oral cavity without the intake of any additional water drawn a great deal of attention. ${ }^{5}$ In present days ODTs for various categories of drugs were developed. ${ }^{6}$

Formulating ODTs of poorly water-soluble drugs also improve its oral bioavailability. But in ODTs, for palatability and patient compliance taste of the drugs plays an important role. Many different oral pharmaceuticals and bulking agents have unpleasant or bittertasting components. So many different formulations are developed with a desire to improve the palatability of the drug by improving performance and suitability. Various technologies were developed for improving the palatability of the drug formulation. ${ }^{7}$ In the present study bitter taste of the drug was masked by mass extrusion technique using Eudragit EPO as a taste masking polymer in different drug-polymer ratios. This technique involves softening the active blends using the water-miscible solvent mixtures and expulsion of the softened mass through extruder or syringes to get a cylinder of products which is then formed into granules using blades or mortar and pestle. The model drug, Mirtazapine (Figure 1) is an atypical antidepressant having noradrenergic and specific serotonergic activity. It belongs to the chemical series called piperazinoazepines. It acts by blocking the histaminergic and muscarinic receptors and enhances serotonin neurotransmission at the $5-\mathrm{HT}_{1}$ receptor. It is a tetracyclic antidepressant that is usually prescribed to patients suffering from major depression and anxiety. A large number of geriatric patients were reported to be receiving this medication. ${ }^{8,9}$ 


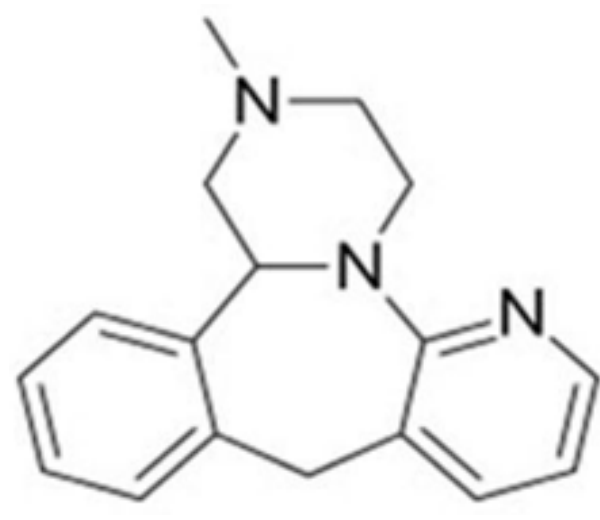

Figure I Chemical Structure of Mirtazapine.

Eudragit EPO (Figure 2), a solid substance obtained from Eudragit E100 polymer was selected for the taste masking. It is a cationic copolymer based on dimethylaminoethyl methacrylate, butylmethacrylate, and methyl methacrylate and chemically known as poly(butyl methacrylate-co-(2 dimethylaminoethyl) methacrylateco-methyl methacrylate. Eudragit EPO shows excellent taste-masking properties even at low film thickness. It can also be used to coat difficult dosage forms, such as multi-particulate fast disintegrating tablets. It is a polymer having low viscosity and high pigment binding capacity and also has good adhesion and low polymer weight gain. It is soluble in gastric $\mathrm{pH}$ up to $5 .{ }^{10-12}$ The oral bioavailability of mirtazapine is found to be roughly $50 \%$ due to first-pass metabolism. ${ }^{8}$ To enhance its oral bioavailability many techniques were used to develop ODT's mirtazapine. However, the major problem associated with this drug is its unpalatable taste. Therefore, in the present study, an attempt was made to mask the bitter taste of mirtzapine by mass extrusion technique using Eudragit EPO in different drug-polymer ratios and later formulated it into more convenient and improved compliance ODTs tablet using different superdisintegrants.<smiles>CCOC(=O)C(C)(CC(C)(C)C(=O)OC)CC(C)(C)C(=O)OCCN(C)C</smiles>

Figure 2 Chemical Structure of Eudragit EPO.

\section{Materials and methods}

Mirtazapine USP and its reference standard were received from Simca Laboratories Pvt. Ltd., Byasi, Bhaktapur, Nepal. Eudragit EPO was received from Evonik Industries Pvt Ltd as a gift sample. Excipients including MCCP 200, talc, magnesium stearate, sodium starch glycollate, croscarmellose sodium, crospovidone, orange flavor, and sucralose were received from Simca Laboratories Pvt. Ltd, Byasi, Bhaktapur, Nepal as a gift sample. All other chemicals used were of chemical grade.

\section{Preparation of mirtazapine drug-polymer complex using Eudragit EPO}

The bitter taste of Mirtazapine USP was masked using Eudragit EPO by mass extrusion technique. ${ }^{13-19}$ The drugs polymer complex (DPC) in ratio of 2:1, 1:1, 1:2 and 1:3 (w/w) were prepared. To prepare granules of the drug-polymer complex, the drug was thoroughly mixed with Eudragit EPO (powdered), as a given amount in Table 1, in mortar and pestle for 10 minutes. Isopropyl alcohol (IPA) was added slowly to the respective drug-polymer mix to form a gel. The prepared gel was extruded manually through a $20 \mathrm{ml}$ plastic syringe to make a thread of the gel. After extrusion solvent from the extruded thread was removed by drying it for 48 hours at room temperature. Subsequently, the solidified gels were crushed using mortar and pestle to obtain drug-polymer granules. Granules thus obtained were then passed through sieve numbers 30 and 60 having a nominal mesh aperture of $590 \mu \mathrm{m}$ and $250 \mu \mathrm{m}$ respectively. The granules passed through each sieve were evaluated separately for taste masking efficacy.

\section{Determination of threshold bitterness concentration of mirtazapine USP}

The bitter taste threshold value of mirtazapine was determined by a single-blind study, based on taste recognition by six healthy volunteers from whom informed consent was obtained. A series of mirtazapine standard solutions of five different concentrations ranging from 50 to $250 \mu \mathrm{g} / \mathrm{ml}$ were prepared in distilled water. Each volunteer was asked to rinse their mouth well with distilled water before tasting. Starting with the lower concentration the volunteers were instructed to taste the standard solution by placing $1 \mathrm{ml}$ of the solution on the center of the tongue. The solution was retained in the mouth for 30 seconds then asked to spat out and then the mouth was thoroughly washed with distilled water. The bitterness level of the taste solution on a numerical scale of 0 : tasteless, 1: very slight (Threshold), 2.0: moderate, and 3: bitter was then recorded and the next higher concentration was tasted after 10 minutes. The threshold value was selected from standard solutions of Mirtazapine as the lowest concentration that produced the sensation of bitter taste in human volunteers. ${ }^{16-23}$

Table I Drug-polymer complex formulation

\begin{tabular}{lllll}
\hline S.N. & Drug-polymer ratio & Weight of drug (g) & Weight of polymer $(\mathrm{g})$ & Amount of IPA (mI) \\
\hline 1 & $2: 01$ & 10 & 5 & 7.5 \\
2 & $1: 01$ & 10 & 10 & 10 \\
3 & $1: 02$ & 10 & 20 & 15 \\
4 & $1: 03$ & 10 & 30 & 20
\end{tabular}




\section{In-vitro evaluation of drug-polymer complex}

The in-vitro taste was evaluated by determining drug release in simulated salivary fluid ( $\mathrm{pH}$ 6.8) to predict release in the human saliva. Drug-polymer complex equivalent to $7.5 \mathrm{mg}$ of Mirtazapine USP was placed in $10 \mathrm{~mL}$ of SSF and shaken for 30 seconds. The above mixture was filtered through Whatman filter paper. The amounts of drug released were analyzed spectrophotometrically at $\lambda_{\max } 289 \mathrm{~nm}$ and were calculated by developing the calibration curve of mirtazapine USP in phosphate buffer of $\mathrm{pH}$ 6.8. If the drug release in SSF is found below the bitterness threshold value, it can be concluded that the bitter taste of the drug can be masked in vivo. ${ }^{20,21}$ Percent drug release in the simulated gastric fluid was determined by dissolving drug-polymer complex (equivalent to $7.5 \mathrm{mg}$ of Mirtazapine USP) in $100 \mathrm{ml}$ of SGF of $\mathrm{pH} 1.2$ and analyzing the samples using UVVisible Spectrophotometer at $\lambda_{\max }, 316 \mathrm{~nm}$. The percentage of drug content was calculated by developing the calibration curve in SGF of $\mathrm{pH} 1.2{ }^{13,24,25}$ An optimum drug-polymer complex that showed sufficient taste masking was selected for further study.

\section{Formulation of oral disintegrating tablets of taste- masked mirtazapine: eudragit EPO granules by disintegrants addition method}

The direct compression method was used for the preparation of oral disintegrating tablets after incorporating superdisintegrants such as Sodium starch glycolate, Croscarmellose sodium, and Crospovidone, in different concentrations. Ten formulations of oral disintegrating tablets of taste-masked mirtazapine were prepared. A randomized design was used for the formulation design in which nine of the formulation contained one of the three disintegrants in different concentrations $(3 \%, 4 \%$, and $5 \%)$, coded $\mathrm{F} 1$ to $\mathrm{F} 9$, and one formulation without the addition of disintegrant for the comparative study coded F10 (Table 2). The designed formulations were of batch sizes 100 tablets per batches and each tablet weight was adjusted to $120 \mathrm{mg}$. The designed formulations were evaluated for different physico-chemical properties. Effects of the addition of different concentrations of superdisintegrants were studied and the best formulation was selected.

Table 2 Formulation Design

\begin{tabular}{lllllllllll}
\hline & FI & F2 & F3 & F4 & F5 & F6 & F7 & F8 & F9 & FI0 \\
\hline DPC (equivalent to MTZ 7.5mg) & 22.5 & 22.5 & 22.5 & 22.5 & 22.5 & 22.5 & 22.5 & 22.5 & 22.5 & 22.5 \\
SSG (3,4,5\%) & 3.6 & 4.8 & 6 & - & - & - & - & - & - & - \\
CCS (3,4,5\%) & - & - & - & 3.6 & 4.8 & 6 & - & - & - & - \\
CPV (3,4,5\%) & - & - & - & - & - & - & 3.6 & 4.8 & 6 & - \\
MCCP 200 (qs) & 87.3 & 86.1 & 84.9 & 87.3 & 86.1 & 84.9 & 87.3 & 86.1 & 84.9 & 90.9 \\
Magnesium Stearate & 1.2 & 1.2 & 1.2 & 1.2 & 1.2 & 1.2 & 1.2 & 1.2 & 1.2 & 1.2 \\
Talc & 1.2 & 1.2 & 1.2 & 1.2 & 1.2 & 1.2 & 1.2 & 1.2 & 1.2 & 1.2 \\
Sucralose & 0.6 & 0.6 & 0.6 & 0.6 & 0.6 & 0.6 & 0.6 & 0.6 & 0.6 & 0.6 \\
Sweet orange flavor & 3.6 & 3.6 & 3.6 & 3.6 & 3.6 & 3.6 & 3.6 & 3.6 & 3.6 & 3.6 \\
Total (mg) & 120 & 120 & 120 & 120 & 120 & 120 & 120 & 120 & 120 & 120
\end{tabular}

\section{Direct compression method}

The orally disintegrating tablets of taste-masked mirtazapine containing $22.5 \mathrm{mg}$ of DPC equivalent to $7.5 \mathrm{mg}$ of mirtazapine USP were prepared by using MCCP 200, as a directly compressible diluent; Sodium starch glycolate, croscarmellose sodium, and Crospovidone were tried as superdisintegrants. The specified quantity of DPC and excipients were weighed precisely. All the excipients were passed through \#60 mesh and were mixed with DPC geometrically in the poly-bag for 5 minutes. The blended powders were compressed in 16 stations rotary compression machine (Cadmach) by using a $7 \mathrm{~mm}$ round biconvex punch with the letter "S" embossed on the upper surface and break-line on the lower surface. The weight of the tablet was maintained to be $120 \mathrm{mg}$.

\section{Evaluation of blended powders}

Blended powders were evaluated for bulk density, tapped density, and carr's compressibility index. All the formulations showed good flow property.

\section{Post compression evaluation of tablet}

Compressed tablets from each batch were evaluated for various parameters like hardness, thickness, weight variation, diameter, and friability percent.

\section{Determination of wetting time}

A piece of tissue paper $(12 \times 10.75 \mathrm{~cm})$ folded twice was placed in a Petri-dish (internal diameter $=9 \mathrm{~cm}$ ) and $10 \mathrm{ml}$ of water containing Eosin is added to it. A tablet is placed on the surface of the tissue paper and the time required for water to reach the upper surface of the tablet is noted as a wetting time. Three tablets from each formulation were randomly selected and the mean \pm standard deviation (sd) for the complete wetting time was measured by three trials for each batch. ${ }^{26-28}$

\section{Determination of in-vitro disintegration time}

The In-vitro disintegration time was determined by using the Disintegration Test Apparatus. The study was carried out in distilled water $(900 \mathrm{ml})$ maintained at temperature $37 \pm 2^{\circ} \mathrm{C}$. One tablet was placed in each of the six tubes of the disintegration apparatus. The time taken for complete disintegration with no palatable mass remaining in the apparatus was measured.

\section{Drug content uniformity}

For the preparation of the standard solution, $50 \mathrm{mg}$ of Mirtazapine was weighed accurately and added to $50 \mathrm{ml}$ of $0.1 \mathrm{~N}$ hydrochloric acid in a volumetric flask. It was then shaken and volume was made up to $100 \mathrm{ml}$ with the medium. $1 \mathrm{ml}$ of the solution was pipette out and diluted to $50 \mathrm{ml}$ with the medium. For the preparation of the sample 
solution, 5 tablets from each batch were taken in a $100 \mathrm{ml}$ volumetric flask, and volume was made up to the mark with $0.1 \mathrm{~N}$ hydrochloric acid. It was then stirred well and filtered separately. $10 \mathrm{ml}$ of the filtered solution was then diluted to $50 \mathrm{ml}$ with the same medium. The absorbance of both the sample and standard solution was measured spectrophotometrically at $316 \mathrm{~nm}$ using $0.1 \mathrm{~N} \mathrm{HCl}$ as blank. The drug content in percentage was calculated by using the formula

$$
\frac{\text { Absorbance of sample }}{\text { Absorbance of standard }} * \frac{\text { Weight of standard }}{100} * \frac{1}{50} * \frac{100}{7.5} * \frac{50}{10} * \% \text { Purity of standard }
$$

An acceptance criterion is 85 to $115 \%$ of the stated amount of Mirtazapine. This procedure was followed for 5 tablets from each formulation. The mean and standard deviation values were calculated.

\section{In-vitro dissolution study}

In-vitro dissolution studies of compressed tablets were conducted using USP type II apparatus (paddle). $900 \mathrm{ml}$ of $0.1 \mathrm{~N} \mathrm{HCl}$ was used as the dissolution medium and paddle rpm was maintained at 50. Aliquot of dissolution medium equal to $10 \mathrm{ml}$ was withdrawn at sampling time 5, 10, and 15 minutes and the dissolution media volume were complemented with a fresh and equal volume of blank media. The aliquot was filtered through Whatman filter paper and the amount of Mirtazapine released from the tablet was determined spectrophotometrically at a wavelength of $316 \mathrm{~nm}$.

\section{Results and discussions}

\section{Determination of threshold bitterness concentration of mirtazapine USP}

During the determination of bitterness threshold concentration, all the volunteers felt the sensation of bitterness, within 30 seconds at the concentration of $100 \mu \mathrm{g} / \mathrm{ml}$. The scoring obtained from the volunteers is summarized in Table 3. From the scoring obtained it was observed that the concentration of $50 \mu \mathrm{g} / \mathrm{ml}$ of mirtazapine USP solution have no detectable bitter taste whereas, concentration $100 \mu \mathrm{g} / \mathrm{ml}$ have a slightly bitter taste that was detectable. The bitterness increased with the increasing concentration of mirtazapine solution. Therefore, it was concluded that the threshold concentration of mirtazapine USP, that trigger the sensation of bitter taste was $100 \mu \mathrm{g} / \mathrm{ml}$. For the drug to be taste-masked, the release of the drug in simulated salivary fluid $(\mathrm{pH}$ 6.8) should be less than the bitterness threshold value.

Table 3 Determination of bitterness threshold value (Scores obtained from volunteers)

\begin{tabular}{llllll}
\hline $\begin{array}{l}\text { Volunteer } \\
\text { Conc. }\end{array}$ & $\begin{array}{l}\mathbf{5 0 \mu g /} \\
\mathbf{m l}\end{array}$ & $\begin{array}{l}\mathbf{l 0 0 \mu \mathrm { g } /} \\
\mathbf{m l}\end{array}$ & $\begin{array}{l}\mathbf{I 5 0 \mu g /} \\
\mathbf{m l}\end{array}$ & $\begin{array}{l}\mathbf{2 0 0 \mu \mathrm { g } /} \\
\mathbf{m l}\end{array}$ & $\begin{array}{l}\mathbf{2 5 0 \mu \mathrm { g } /} \\
\mathbf{m l}\end{array}$ \\
\hline $\mathrm{A}$ & 0 & $\mathrm{I}$ & 2 & 2 & 3 \\
$\mathrm{~B}$ & 0 & $\mathrm{I}$ & $\mathrm{I}$ & 2 & 2 \\
$\mathrm{C}$ & 0 & $\mathrm{I}$ & 2 & 2 & 3 \\
$\mathrm{D}$ & 0 & $\mathrm{I}$ & 2 & 3 & 3 \\
E & 0 & $\mathrm{I}$ & 2 & 2 & 3 \\
F & 0 & $\mathrm{I}$ & $\mathrm{I}$ & 2 & 3
\end{tabular}

[0: tasteless, I: very slight (Threshold), 2: moderate, 3: bitter]

\section{Calibration curve}

Determination of calibration curve in phosphate buffer of $\mathrm{pH} 6.8$

From the scanning of mirtazapine in UV/Vis spectrophotometer, $\lambda_{\max }$ of mirtazapine was found at $289 \mathrm{~nm}$ in phosphate buffer $\mathrm{pH}$ 6.8 . So, the wavelength of $289 \mathrm{~nm}$ was used for further observations.
Dilute solution of $(7.53 \mu \mathrm{g} / \mathrm{ml}, 15.06 \mu \mathrm{g} / \mathrm{ml}, 22.59 \mu \mathrm{g} / \mathrm{ml}, 30.12 \mu \mathrm{g} / \mathrm{ml}$, and $37.65 \mu \mathrm{g} / \mathrm{ml}$ ) mirtazapine were prepared in phosphate buffer of pH 6.8 for mirtazapine USP reference standard (RS). The absorbance of the individual solution was observed at $289 \mathrm{~nm}$ in a UV-visible spectrophotometer (Shimadzu 1800). A calibration curve was prepared by plotting absorbance versus concentration of mirtazapine. The linear regression equation obtained for the mirtazapine calibration curve in phosphate buffer of $\mathrm{pH} 6.8$ at $289 \mathrm{~nm}$ was $\left[0.025^{*}\right.$ concentration in $\mu \mathrm{g} /$ $\mathrm{ml}$ ] -0.008 with the regression coefficient of 0.998 which suggested a good correlation among the measured values. The absorbances obtained from these sample solutions are given in Table 4 . The plotted calibration curve for mirtazapine RS in phosphate buffer of $\mathrm{pH} 6.8$ is given in Figure 3.1.

Table 4 Absorbance for various concentration of mirtazapine solution in phosphate buffer of $\mathrm{pH} 6.8$

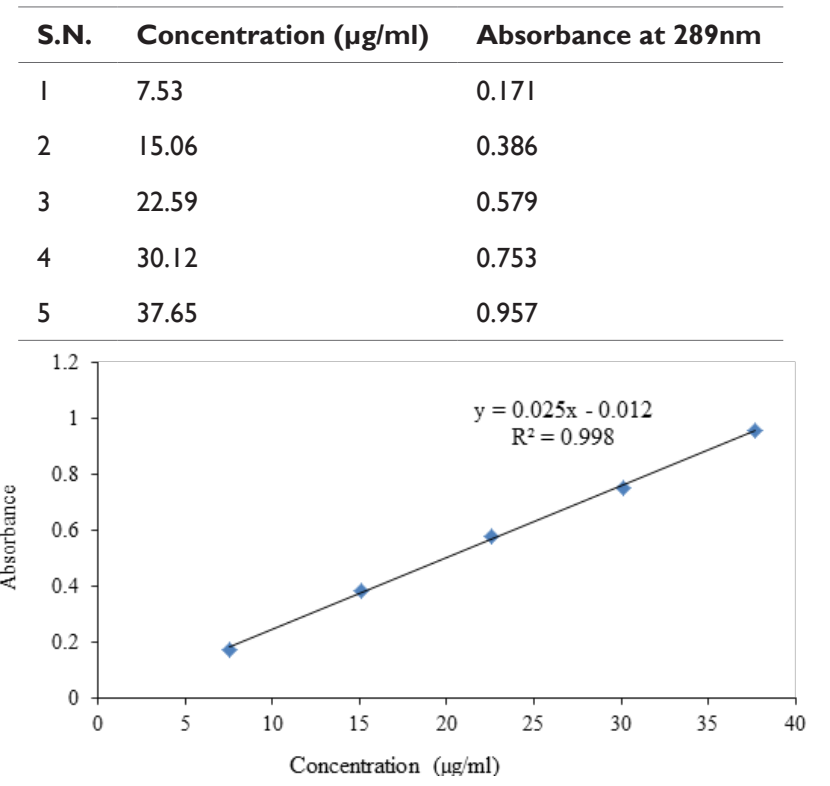

Figure 3.I Calibration curve of Mirtazapine USP RS in Phosphate buffer $(\mathrm{pH}$ 6.8).

\section{Determination of calibration curve in $0.1 \mathrm{~N} \mathrm{HCl}(\mathrm{pH} 1.2)$}

From the scanning of mirtazapine in UV/Vis spectrophotometer, $\lambda_{\max }$ of mirtazapine was found at $316 \mathrm{~nm}$ in $0.1 \mathrm{~N} \mathrm{HCl} \mathrm{pH} 1.2$. So, the wavelength of $316 \mathrm{~nm}$ was used for further observations. Dilute solutions of $(4.032,8.064,12.096,16.128$, and $20.16 \mu \mathrm{g} / \mathrm{ml})$ mirtazapine were prepared in $0.1 \mathrm{~N} \mathrm{HCl}$ of $\mathrm{pH} 1.2$ for mirtazapine USP RS. The absorbance of the individual solution was observed at 316 $\mathrm{nm}$ in a UV-visible spectrophotometer (Shimadzu 1800). A calibration curve was prepared by plotting absorbance versus concentration of mirtazapine.

The linear regression equation obtained for the mirtazapine calibration curve in $0.1 \mathrm{~N} \mathrm{HCl}$ at $316 \mathrm{~nm}$ was $[0.039 \mathrm{X}$ concentration in $\mu \mathrm{g} / \mathrm{ml}]-0.02$ with the regression coefficient of 0.999 which suggested 
linear correlation among the measured values. The absorbance's obtained from these sample solutions are given in Table 5. The plotted calibration curve for mirtazapine $\mathrm{RS}$ in $0.1 \mathrm{~N} \mathrm{HCl}$ is given in Figure 3.2.

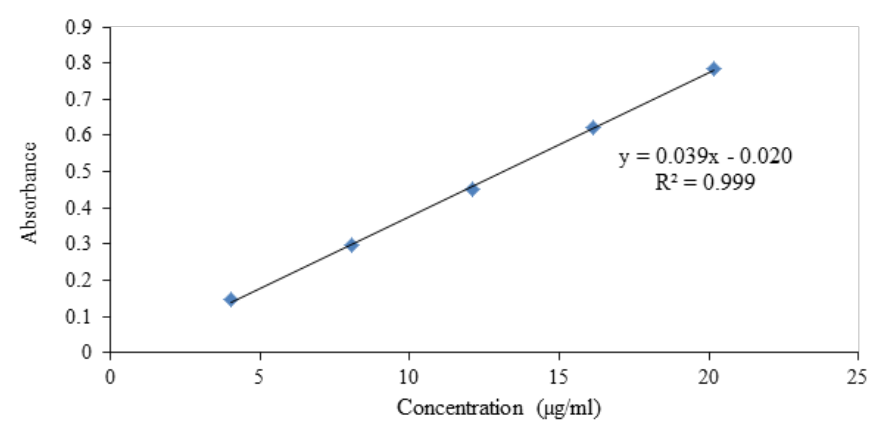

Figure 3.2 Calibration curve of Mirtazapine USP RS in $0.1 \mathrm{~N} \mathrm{HCl}(\mathrm{pH}$ I.2).

Table 5 Absorbance for various concentration of mirtazapine solution in $0.1 \mathrm{~N} \mathrm{HCl}$

\begin{tabular}{lll}
\hline S.N. & Concentration $(\mu \mathrm{g} / \mathrm{ml})$ & Absorbance at $316 \mathrm{~nm}$ \\
\hline $\mathrm{I}$ & 4.032 & 0.145 \\
2 & 8.064 & 0.297 \\
3 & 12.096 & 0.45 \\
4 & 16.128 & 0.621 \\
5 & 20.16 & 0.784
\end{tabular}

\section{In-vitro evaluation of taste-masked drug-polymer complex}

In this research taste-masked granules of mirtazapine were prepared using Eudragit EPO polymer by mass extrusion technique. Different ratios of the drug-polymer complex were prepared and tested for taste masking efficacy. For the evaluation of the taste masking effectiveness of the different drug-polymer ratio, it was subjected to a simple Invitro release study in phosphate buffer of $\mathrm{pH}$ 6.8. The result of the percentage drug release of drug solution in four different drugs: polymer complex of different particle sizes is summarized in Table 6 . From the result, it was found that the taste of the drugs has been masked by the use of Eudragit EPO polymer by mass extrusion technique. It was found that with the increasing concentration of the Eudragit EPO the percentage of drug release in SSF decreased. The concentration of the drug release in granules with the drug: polymer ratio 2:1 and $1: 1$ was found to be higher than that of the bitterness threshold value which signified the failure to mask the bitter taste effectively. Also, it was observed that the particle size of the granules affected the drug release in phosphate buffer of $\mathrm{pH}$ 6.8. In the case of granules with smaller particle size (i.e particles $<250 \mu \mathrm{m}$ ), the percentage drug release in phosphate buffer was found to be higher compared to that of the larger particle size $(250-590 \mu \mathrm{m})$. This is due to the larger surface area for the dissolution of the drug-polymer complex. The decrease in particle size increases the relative surface area. With the increase in the relative surface area, the possibility of the un-entrapped drug on the surface of the complex will also increase. Besides the increased surfaced area, dissolution of drugs on the surface of the particle might be the reason for the increased drug release percentage in the case of the smaller particles drug-polymer complex. However, the percentage of drug release in simulated gastric fluid $(0.1 \mathrm{~N} \mathrm{HCl} \mathrm{pH} \mathrm{1.2)} \mathrm{was} \mathrm{found}$ to be independent of the particle size. The polymer, Eudragit EPO used for the taste masking is soluble in lower $\mathrm{pH}$ values (at gastric $\mathrm{pH})$. The drug-polymer complex completely dissolved in lower $\mathrm{pH}$ values.
Table 6 Percent Drug release in SSF and SGF from DPC

\begin{tabular}{lllll}
\hline S.N. & DPC & $\begin{array}{l}\text { Particle } \\
\text { size }\end{array}$ & $\begin{array}{l}\text { \%Drug release } \\
\text { in SSF }(\mathbf{p H ~ 6 . 8})\end{array}$ & $\begin{array}{l}\text { \% Drug release } \\
\text { in SGF }(\mathbf{p H ~ I . 2 )}\end{array}$ \\
\hline 1 & $2: 01$ & $<250 \mu \mathrm{m}$ & $18.79 \pm 0.36$ & $99.67 \pm 0.23$ \\
2 & $2: 01$ & $590-250 \mu \mathrm{m}$ & $14.82 \pm 0.64$ & $97.98 \pm 0.30$ \\
3 & $1: 01$ & $<250 \mu \mathrm{m}$ & $15.87 \pm 0.11$ & $104.44 \pm 0.30$ \\
4 & $1: 01$ & $590-250 \mu \mathrm{m}$ & $4.78 \pm 0.01$ & $101.47 \pm 0.26$ \\
5 & $1: 02$ & $<250 \mu \mathrm{m}$ & $7.92 \pm 0.02$ & $103.59 \pm 0.17$ \\
6 & $1: 02$ & $590-250 \mu \mathrm{m}$ & $4.21 \pm 0.10$ & $97.66 \pm 0.53$ \\
7 & $1: 03$ & $<250 \mu \mathrm{m}$ & $6.63 \pm 0.41$ & $103.73 \pm 0.41$ \\
8 & $1: 03$ & $590-250 \mu \mathrm{m}$ & $3.96 \pm 0.03$ & $99.77 \pm 0.4$ \\
\hline
\end{tabular}

From the result, it was found that the amount of Mirtazapine dissolved from the drug-polymer complex within 30 seconds decreased with increased concentration of Eudragit EPO. The result of drug concentration in SSF is summarized in Figure 3.3. The drug: polymer complex will be considered optimum and will be used for taste masking if it yields a drug release value below the threshold concentration $(100 \mu \mathrm{g} / \mathrm{ml})$. It was observed that the mirtazapine complexed with Eudragit EPO in the proportion of 1:2 showed drug release values below $100 \mu \mathrm{g} / \mathrm{ml}$ for both particle size ranges. The observed drug release, in phosphate buffer $\mathrm{pH} 6.8$ from the drug: polymer in the ratio $1: 2$ at the end of 30 seconds is $59.37 \pm 0.16 \mu \mathrm{g} /$ $\mathrm{ml}$ for particle size $<250 \mu \mathrm{m}$ and $31.10 \pm 0.08 \mu \mathrm{g} / \mathrm{ml}$ for particle range $590-250 \mu \mathrm{m}$. The FTIR spectra of the drug, Eudragit EPO, physical mixture, and the taste-masked granules in the ratio 1:2 were studied. There were no major changes in the FTIR spectra of the taste-masked granules indicating the absence of any chemical reaction in between mirtazapine and the polymer. Thus it was concluded that the drug: Eudragit EPO in proportion 1:2 was optimum for masking the bitter taste of mirtazapine and this drug-polymer ratio was selected for further study.

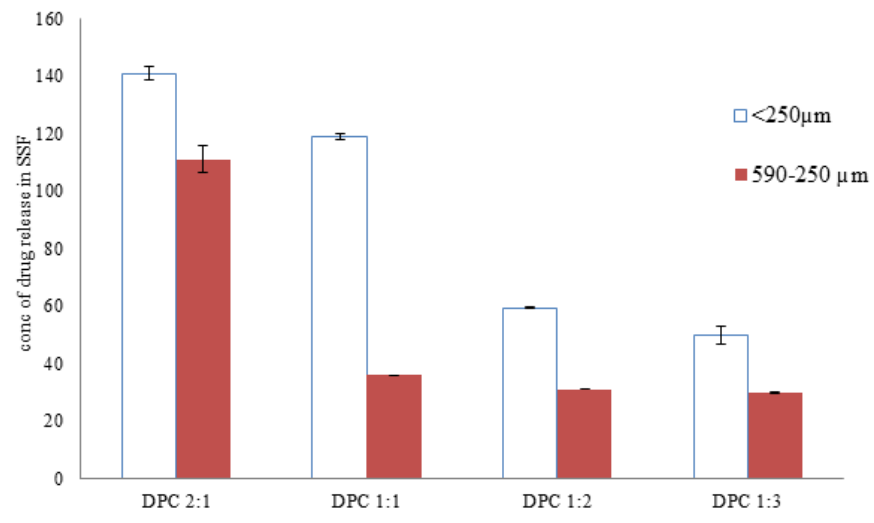

Figure 3.3 Drug release in SSF $(\mathrm{pH} 6.8)$.

\section{Micrometric properties of lubricated granules}

The blended powders were evaluated for bulk density, tapped density, and carr's compressibility index, and Hausner's ratio. The bulk density $(\mathrm{Db})$ was found to be in the range from $0.412 \pm 0.04$ (F1) to $0.497 \pm 0.05$ (F7). The tapped density (Dt) was found to be in the range $0.492 \pm 0.02$ (F1) to $0.593 \pm 0.06$ (F10). From the bulk and tapped density, Carr's compressibility index (I) was found in the range from $14.26 \pm 1.27$ (F9) to $18.46 \pm 2.01$ (F3). From this data, it was found that all the formulations (except formulation F3) showed good flow property however formulation F3 showed fairly passable flow ability. This fact was also supported by the Hausner's ratio. The Hausner's 
ratio was found to be in the range from $1.16 \pm 0.02$ (F9) to $1.22 \pm 0.00$ (F3). The Hausner's ratio of all the formulation was found below value 1.25 (Table 7).

Table 7 Micrometric properties of lubricated granules

\begin{tabular}{lllll}
\hline Batch & $\begin{array}{l}\text { Bulk } \\
\text { Density } \\
\text { (g/cc) }\end{array}$ & $\begin{array}{l}\text { Tapped } \\
\text { Density (g/ } \\
\text { cc) Density }\end{array}$ & $\begin{array}{l}\text { Carr's } \\
\text { Compressibility } \\
\text { Index (\%)o } \\
\text { Index }\end{array}$ & $\begin{array}{l}\text { Hausner's } \\
\text { Ratio }\end{array}$ \\
\hline FI & $0.412 \pm 0.04$ & $0.492 \pm 0.02$ & $16.26 \pm 1.43$ & $1.19 \pm 0.02$ \\
F2 & $0.425 \pm 0.08$ & $0.504 \pm 0.03$ & $15.67 \pm 1.03$ & $1.18 \pm 0.01$ \\
F3 & $0.468 \pm 0.02$ & $0.574 \pm 0.03$ & $18.46 \pm 2.01$ & $1.22 \pm 0.00$ \\
F4 & $0.472 \pm 0.06$ & $0.574 \pm 0.01$ & $17.77 \pm 1.54$ & $1.21 \pm 0.01$ \\
F5 & $0.458 \pm 0.05$ & $0.548 \pm 0.03$ & $16.42 \pm 1.86$ & $1.19 \pm 0.02$ \\
F6 & $0.478 \pm 0.04$ & $0.572 \pm 0.00$ & $16.43 \pm 1.14$ & $1.19 \pm 0.04$ \\
F7 & $0.497 \pm 0.05$ & $0.593 \pm 0.04$ & $16.18 \pm 1.46$ & $1.19 \pm 0.00$ \\
F8 & $0.453 \pm 0.00$ & $0.538 \pm 0.01$ & $15.79 \pm 1.38$ & $1.18 \pm 0.03$ \\
F9 & $0.487 \pm 0.03$ & $0.568 \pm 0.03$ & $14.26 \pm 1.27$ & $1.16 \pm 0.02$ \\
FI0 & $0.496 \pm 0.06$ & $0.593 \pm 0.06$ & $16.35 \pm 1.34$ & $1.19 \pm 0.02$ \\
\hline
\end{tabular}

\section{Evaluation of physicochemical properties of formulated taste-masked mirtazapine orodispersible} tablets

Each formulated tablets was characterized by Physico-chemical properties- appearance, weight variation, hardness, thickness, friability, wetting time, disintegration time, percentage drug release, and drug content (assay). The intended weight of the tablet was $120 \mathrm{mg}$. The tablets obtained are of $7 \mathrm{~mm}$ round, biconvex, embossed with letter "S" on the upper surface and break-line on the lower surface. The tablet weight of the formulated batches was found to be in the range of $117 \mathrm{mg}$ to $123 \mathrm{mg}$. The maximum deviation obtained was $\pm 2.5 \%$. The average tablet hardness was in the range of $3.8 \pm 0.27$ to $4 \pm 0.00 \mathrm{Kg}$. The average thickness was found in the range of $3.290 \pm 0.012$ to $3.310 \pm 0.023 \mathrm{~mm}$. The average diameter was in the range of $7.00 \pm 0.00$ to $7.01 \pm 0.02 \mathrm{~mm}$ (Table 8). The minimum average wetting time was found with the formulation F9 and the value obtained was $18.13 \pm 0.24$ seconds. The friability was found in the range of $0-0.13 \%$ which was found to be well within the approved range $(<1 \%)$. This showed the tablet's ability to withstand abrasion in handling. The drug content uniformity was found to be between $97.94 \pm 0.17$ to $99.70 \pm 0.47$ percent.

Table 8 Evaluation of Physicochemical Characteristics of Formulated Batches

\begin{tabular}{lllll}
\hline Batch & $\begin{array}{l}\text { Diameter } \\
(\mathbf{n}=5) \mathbf{m m}\end{array}$ & $\begin{array}{l}\text { Thickness } \\
(\mathbf{n}=5) \mathbf{m m}\end{array}$ & $\begin{array}{l}\text { Hardness } \\
(\mathbf{n}=5) \mathbf{~ K g}\end{array}$ & \% Friability \\
\hline FI & $7.00 \pm 0.00$ & $3.30 \pm 0.02$ & $3.80 \pm 0.27$ & 0.04 \\
F2 & $7.01 \pm 0.00$ & $3.29 \pm 0.01$ & $3.90 \pm 0.22$ & 0.07 \\
F3 & $7.00 \pm 0.00$ & $3.31 \pm 0.01$ & $4.00 \pm 0.00$ & 0 \\
F4 & $7.00 \pm 0.00$ & $3.31 \pm 0.02$ & $3.80 \pm 0.27$ & 0.08 \\
F5 & $7.01 \pm 0.01$ & $3.30 \pm 0.01$ & $3.70 \pm 0.27$ & 0.1 \\
F6 & $7.01 \pm 0.01$ & $3.30 \pm 0.02$ & $4.00 \pm 0.00$ & 0.08 \\
F7 & $7.00 \pm 0.00$ & $3.31 \pm 0.01$ & $4.00 \pm 0.00$ & 0.06 \\
F8 & $7.01 \pm 0.01$ & $3.30 \pm 0.02$ & $3.90 \pm 0.22$ & 0.13 \\
F9 & $7.01 \pm 0.00$ & $3.31 \pm 0.01$ & $4.00 \pm 0.00$ & 0.05 \\
F10 & $7.00 \pm 0.00$ & $3.30 \pm 0.02$ & $4.00 \pm 0.00$ & 0.07 \\
\hline
\end{tabular}

\section{Disintegration time}

The disintegration time is one of the much important factors in the formulation of an Orodispersible tablet. The present study aimed to keep the disintegration time less than 1 minute. Ten batches were formulated using different super disintegrates in three levels of concentrations with one controlled formulation without the addition of super disintegrants. The disintegration time was found to be in the range of $13.6 \pm 2.70$ seconds to $117 \pm 5.7$ seconds. Graphical representation of the disintegration time of formulated batches of different super disintegrants is as shown in Figure 3.4(A-C). The graphical representation of the disintegration time of formulated batches using the super disintegrants showed that the formulation containing crospovidone 5\% (F9) showed the least disintegration time (13.6 \pm 2.7 seconds) among all the formulations. The control formulation without super disintegrants showed the maximum disintegration time (117 \pm 5.7 seconds). Disintegration time decreased with increasing concentration of super disintegrants.
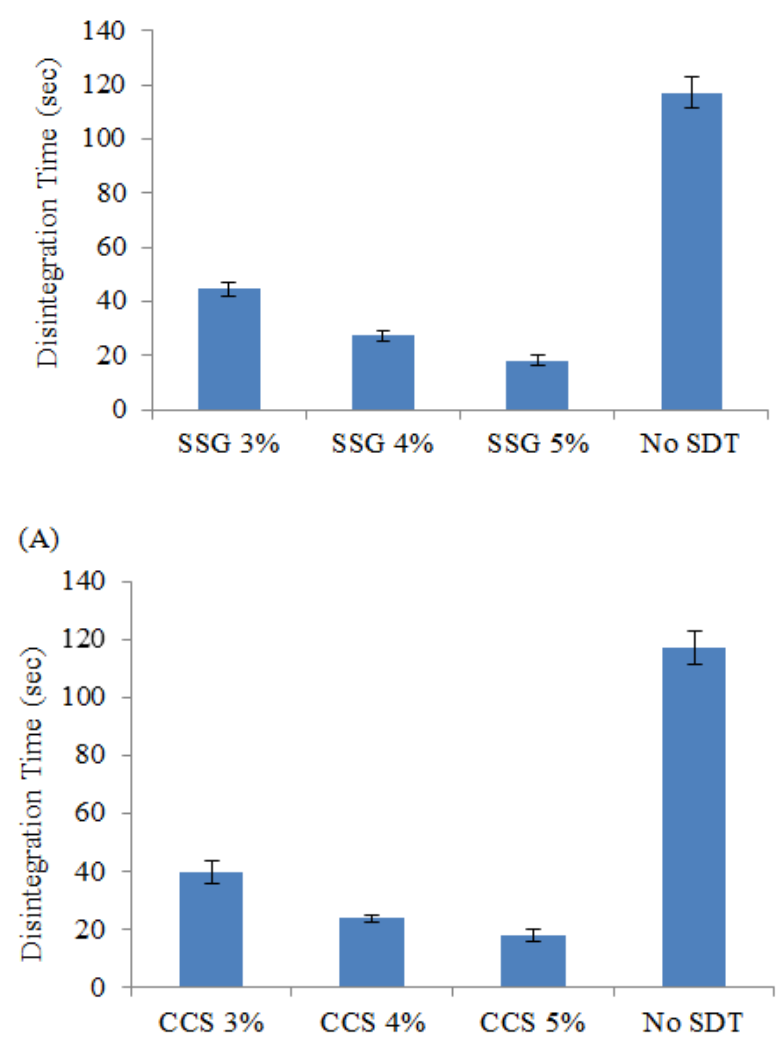

(B)

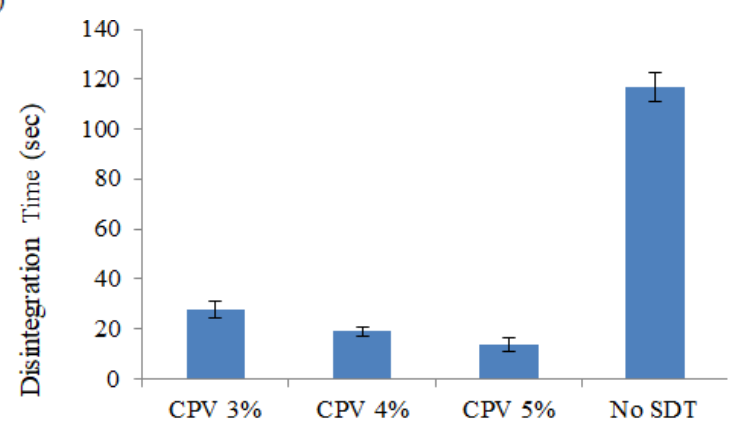

(C)

Figure 3.4 Comparative study of disintegration time of formulated batches (a) with SSG in different concentrations; (b) with CCS in different concentrations (c) with CPV in different concentrations. 


\section{Wetting time}

Wetting time is one of the most important factors in the formulation of an orodispersible tablet. It corresponds to the time taken for the tablet to disintegrate while keeping motionless on the tongue. The minimum wetting time was found to be $18.13 \pm 0.24$ seconds with the formulation containing $5 \%$ of crospovidone (F9). The maximum wetting time was found to be $126.04 \pm 1.42$ seconds with the controlled formulation without the addition of super disintegrants (Table 9). The graphical representation of the wetting time of all batches formulated with the super disintegrants and without the addition of super disintegrants is shown in Figure 3.5(A-C).

Table 9 Analytical data of Formulated Batches

\begin{tabular}{lllll}
\hline Batches & $\begin{array}{l}\text { Disintegration } \\
\text { time }(\mathrm{sec}) \\
(\mathbf{n = 6})\end{array}$ & $\begin{array}{l}\text { Wetting } \\
\text { time }(\mathrm{sec}) \\
(\mathbf{n = 3})\end{array}$ & $\begin{array}{l}\text { Cumulative } \\
\% \text { drug } \\
\text { release } \\
(\mathbf{n = 6})\end{array}$ & $\begin{array}{l}\text { Drug } \\
\text { content } \\
\text { uniformity } \\
(\mathbf{n}=5)\end{array}$ \\
\hline FI & $46.6 \pm 2.70$ & $77.47 \pm 1.76$ & $94.63 \pm 1.26$ & $98.95 \pm 0.15$ \\
F2 & $27.4 \pm 1.81$ & $40.32 \pm 1.54$ & $99.39 \pm 0.90$ & $98.06 \pm 0.17$ \\
F3 & $18.2 \pm 2.05$ & $21.61 \pm 1.689$ & $97.56 \pm 1.14$ & $98.07 \pm 0.23$ \\
F4 & $39.8 \pm 3.70$ & $44.45 \pm 0.67$ & $92.49 \pm 1.78$ & $97.94 \pm 0.17$ \\
F5 & $23.8 \pm 1.09$ & $35.52 \pm 3.06$ & $93.95 \pm 3.21$ & $99.20 \pm 0.42$ \\
F6 & $18 \pm 1.87$ & $28.43 \pm 1.04$ & $96.84 \pm 2.31$ & $99.70 \pm 0.47$ \\
F7 & $27.8 \pm 3.34$ & $39.25 \pm 1.48$ & $97.68 \pm 2.18$ & $98.98 \pm 0.20$ \\
F8 & $19 \pm 2$ & $26.32 \pm 0.561$ & $96.88 \pm 1.63$ & $98.99 \pm 0.18$ \\
F9 & $13.6 \pm 2.70$ & $18.13 \pm 0.24$ & $101.32 \pm 1.54$ & $98.05 \pm 0.35$ \\
FI0 & $117 \pm 5.7$ & $126.04 \pm 1.42$ & $96.24 \pm 2.45$ & $98.67 \pm 0.31$
\end{tabular}

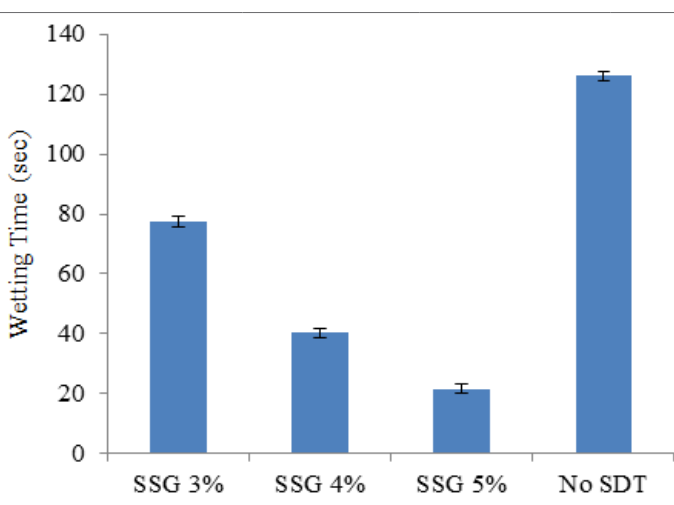

(A)

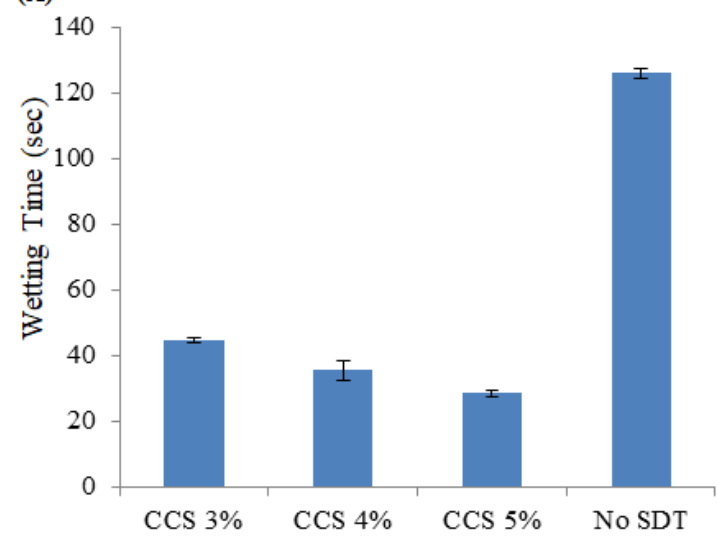

(B)

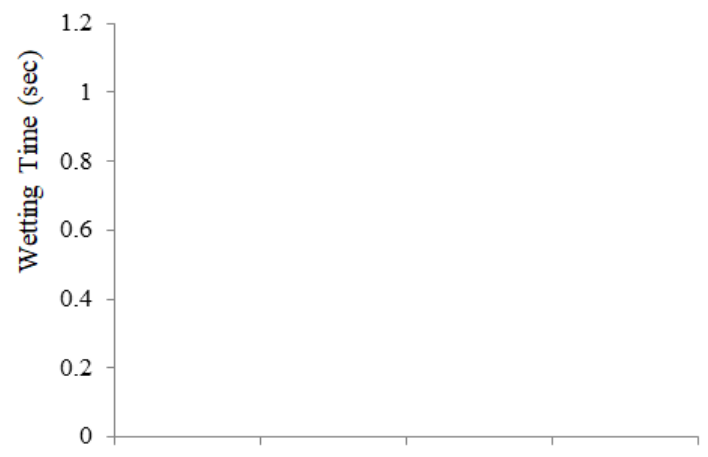

(C)

Figure 3.5 Comparative study of wetting time of formulated batches $(A)$ with SSG in different concentrations; (B) with CCS in different concentrations; (C) with $\mathrm{CPV}$ in different concentrations.

\section{Effect of super disintegrants in disintegration time and wetting time}

Disintegration time, wetting time, and dissolution profile are the most important parameters that needed to be optimized in the development of an oral-dispersible tablet. In the present study, 9 different batches of tablets containing SSG, CCS, and CPV in three different concentrations $(3,4$, and $5 \%$ ) individually and a controlled formulation without the addition of superdisintegrants (F10) were prepared by direct compression method. Tablets of all batches disintegrated and wetted within a matter of seconds (except the controlled formulation). The disintegration and wetting time were observed to follow the order $\mathrm{CPV}<\mathrm{CCS}<\mathrm{SSG}$. The minimum disintegration time was found to be $13.6 \pm 2.7$ seconds and the minimum wetting time was found to be $18.13 \pm 0.24$ seconds with the formulation containing $\mathrm{CPV}$ in $5 \%$. In the case of $\mathrm{SSG}$, the major mechanism of disintegration is rapid and extensive swelling by minimal gelling. It was observed that there was a trend of lower wetting and disintegration time using higher levels of these excipients despite similar mechanical strengths. These indicated that a higher amount of this excipient is necessary for effective disintegration. Croscarmellose sodium functions by a combination of mechanisms to cause rapid tablet breakdown. It works by a combination of swelling, wicking, and deformation. However, water uptake (wicking) and swelling are the two most important mechanisms of disintegrant action of croscarmellose sodium. It has water uptake and water wicking capabilities provided by its fibrous structure. Due to the water wicking capabilities of CCS, its disintegration time was found to be smaller than that of the SSG. The increasing concentration of these superdisintegrants decreases the wetting time as well as the disintegration time.

Compared to SSG and CCS, CPV with the same concentration showed a better result in terms of disintegration time and wetting time that is the disintegration and wetting time was found to be lower. This might be due to the highly hydrophilic character, rapid moisture sorption, and good swell ability of this super disintegrant. It has very high capillary activity and hydration capacity due to its reasonably large surface area. The water uptake causes an instant expansion of the polymer due to stretching out of the folded molecular chains lying between the crosslinks. The increase in volume creates an internal pressure exceeding that of the tablet strength and results in faster disintegration of the tablet body. It allows faster wetting of the tablet, creating a super disintegrant network around the particles and it might also prevent the strong cohesive bond between the filled 
particles due to high specific surface area. Therefore, the wetted tablet disintegrated fast irrespective of the actual hardness value. The minimal disintegration time and wetting time were found to be $13.6 \pm 2.70$ seconds $(n=3)$ and $18.13 \pm 0.24$ seconds $(n=3)$ respectively with the formulation containing crospovidone in $5 \%$ (Table 9 ).

\section{In-vitro dissolution studies}

In-vitro dissolution tests were conducted using USP apparatus II (paddle) at $37 \pm 0.5^{\circ} \mathrm{C}$ at a rotational speed of $50 \mathrm{RPM}$ in $900 \mathrm{ml}$ of $0.1 \mathrm{~N}$ Hydrochloric acid ( $\mathrm{pH} 1.2)$ medium for all formulations. A 10 $\mathrm{ml}$ of sample was taken from the medium after 5, 10, and 15 minutes and the percent drug release was calculated by measuring absorbance spectrophotometrically at $316 \mathrm{~nm}$. The cumulative percent drug release in all the formulations after 15 minutes showed satisfactory results. It was found in the range of $92.49 \pm 1.78 \%$ to $101.32 \pm 1.54 \%$. The result showed that there is no significant difference in cumulative percent drug release due to both the types and concentration of superdisintegrants used $(\mathrm{P}>0.05)$. A comparative dissolution profile of different batches is shown in Figure 3.6(A)-3.6(C).
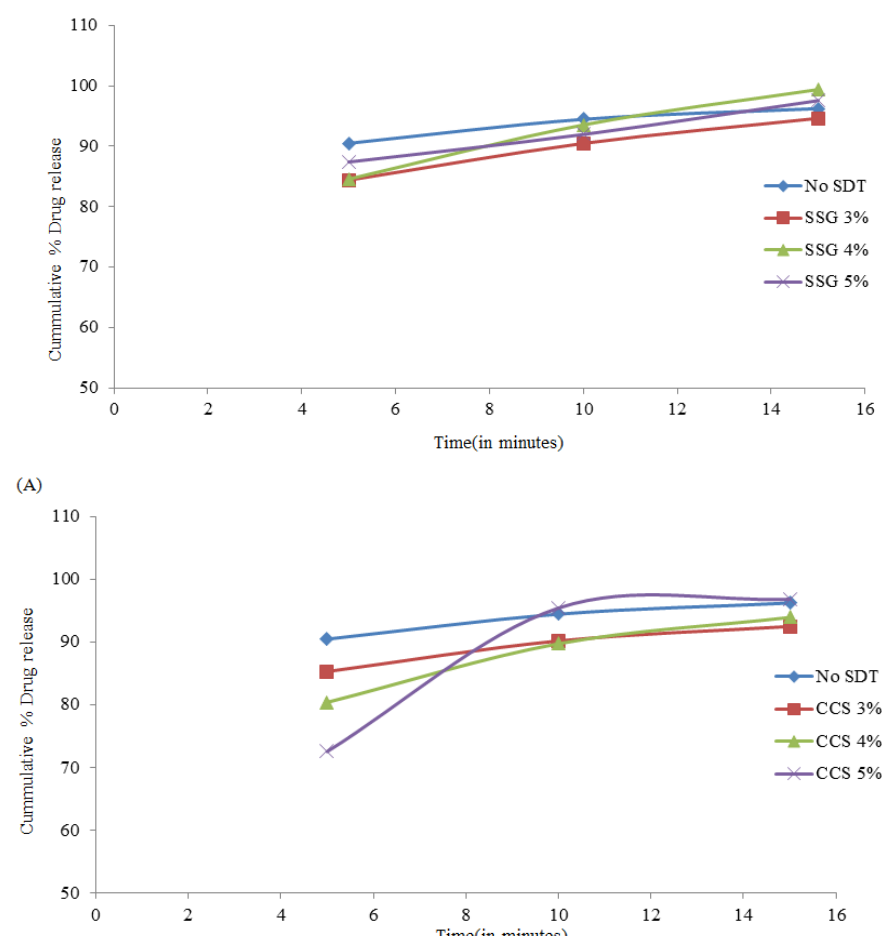

(B)

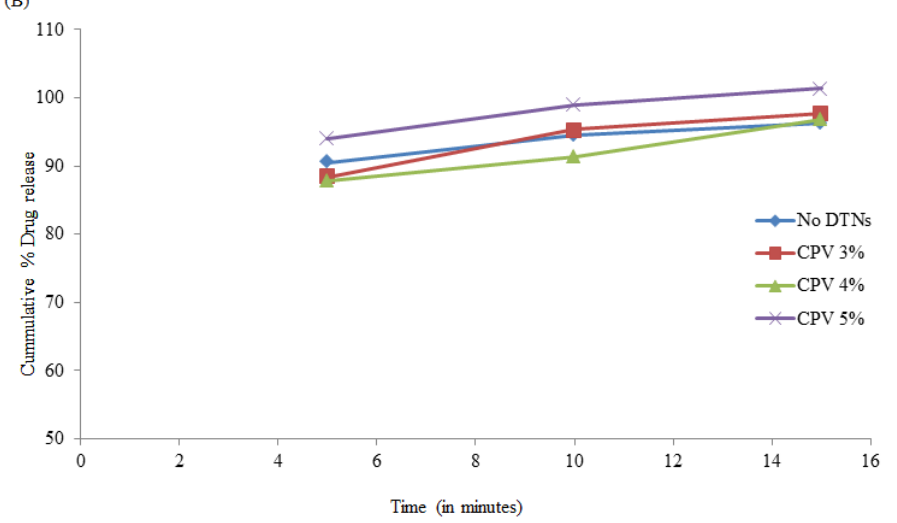

(C)

Figure 3.6 Comparative dissolution profile of formulation containing (a) SSG; (b) CCS; (c) CPV (3, 4, and 5\%).

\section{Selection and characterization of the best formulation}

Tablets of batch F9 (CPV 5\%) depicted the best physical properties accompanied by the fastest disintegration time (13.6 \pm 2.70 seconds) and wetting time ( $18.13 \pm 0.24$ seconds). The dissolution study of this batch revealed a rapid release of the drug $(94.02 \%$ of the drug) within 5 minutes. The tablets were evaluated for the percent drug release in simulated salivary fluid (phosphate buffer of $\mathrm{pH}$ 6.8). The dissolution profile of this batch in phosphate buffer of $\mathrm{pH} 6.8$ (Figure 3.7) showed that at the end of the 5 minutes less than $10 \%$ of the drug was released. This showed that the drug release rate from the ODT was similar to that of the taste-masked granules. The $\%$ drug release in phosphate buffer for 5 minutes reveals and is reasonable to conclude that direct compression did not affect those attributes of the taste-masked granules responsible for the release of the drug.

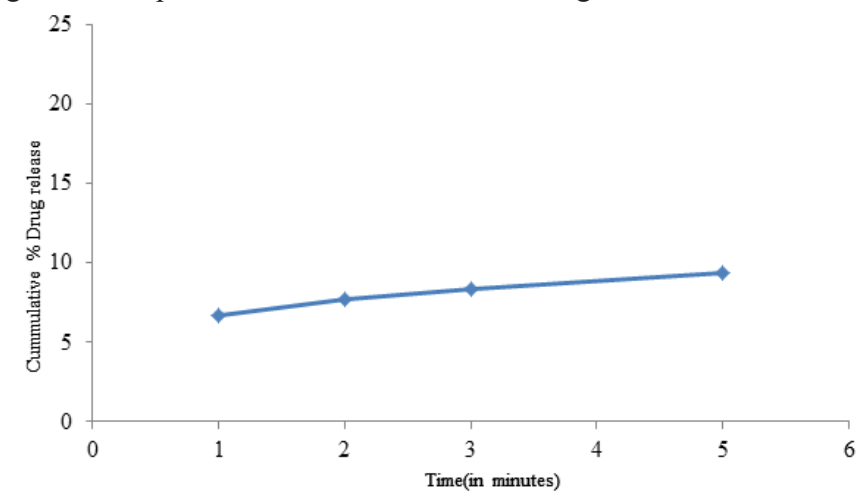

Figure 3.7 In-vitro drug release profile of batch F9 in phosphate buffer of $\mathrm{pH}$ 6.8 .

\section{Drug-excipient compatibility testing of selected formulation}

The compatibility study of active with inactive ingredients was conducted in a 1:1 ratio for the selected formulation. Isothermal stress testing was carried out for the assessment of the possible incompatibilities.

The binary samples prepared were analyzed using FTIR for any chemical changes. FTIR peaks of controlled and test samples are presented in Figure 3.8(A)-3.8(I). with the major functional group's absorption frequencies for API and excipients. IR spectroscopy of mirtazapine Figure 3.8(A) shows the $\mathrm{C}-\mathrm{H}$ stretching vibration band of a methyl group at $2931 \mathrm{~cm}^{-1}$. Methyl groups attached to an $\mathrm{N}_{2}$ atom give rise to a band at $2854 \mathrm{~cm}^{-1}$. Bands for the C-C stretching of the phenyl group appeared at $1585 \mathrm{~cm}^{-1}$ and $1444 \mathrm{~cm}^{-1}$. The primary aromatic amines with $\mathrm{N}$ directly on the ring give bands at 1336-1200 $\mathrm{cm}^{-1}$. The benzene ring C-H appears in the range of 1359-1074 $\mathrm{cm}^{-1}$ and $788-636 \mathrm{~cm}^{-1}$ for the in-plane and out of plane bending vibrations respectively.

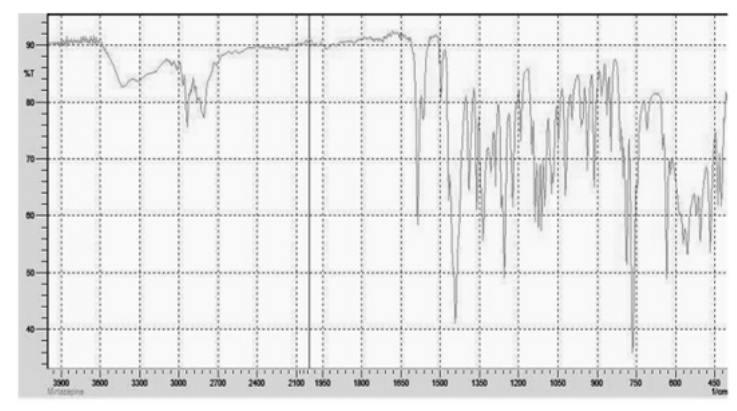

(A) 


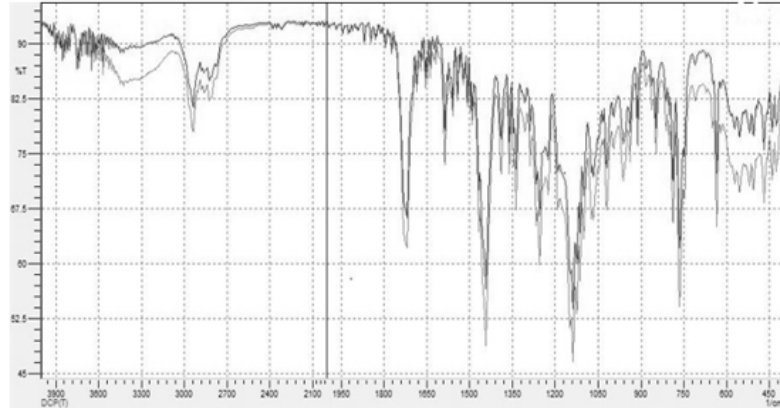

(B)

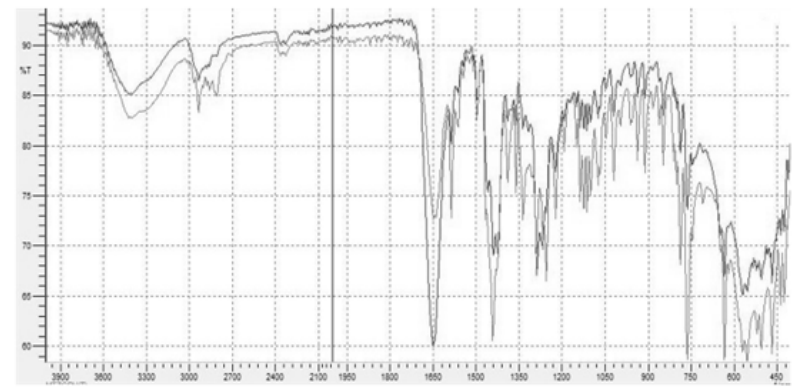

(C)

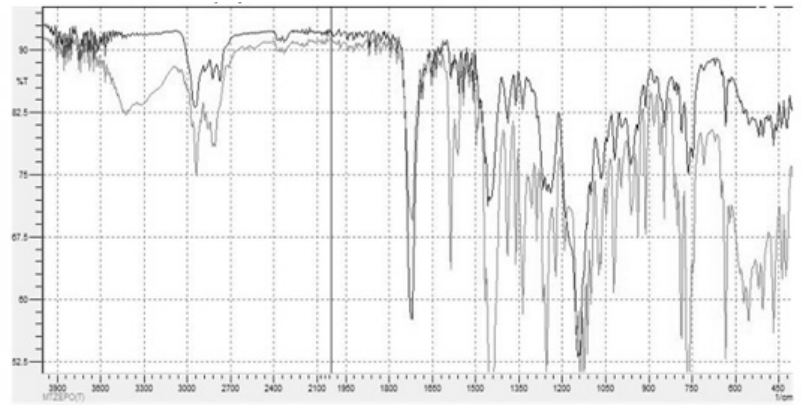

(D)

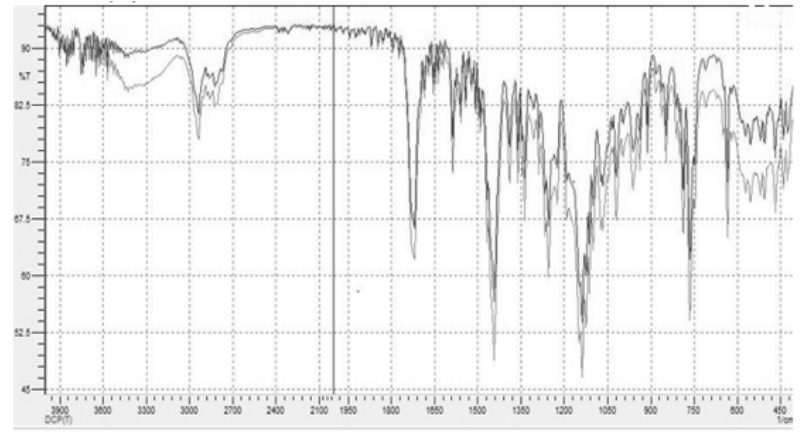

(E)

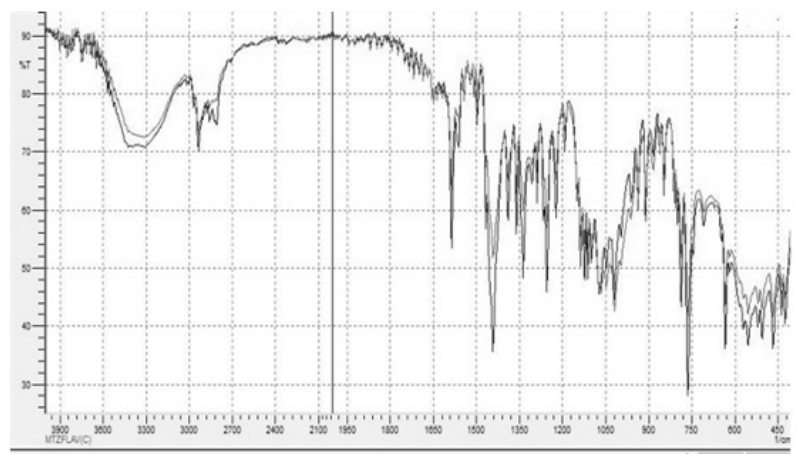

(F)

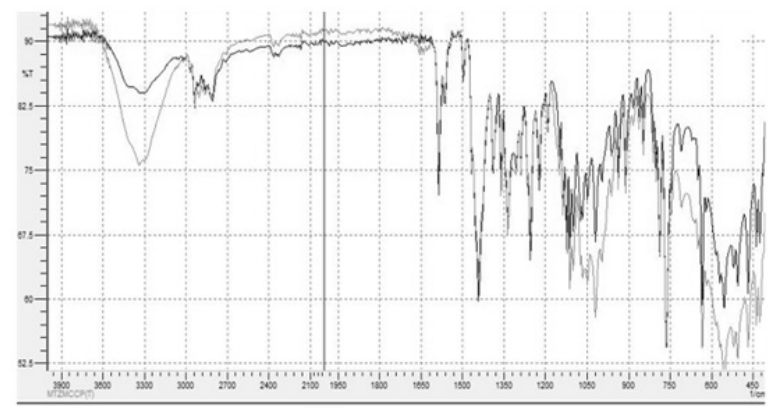

(G)

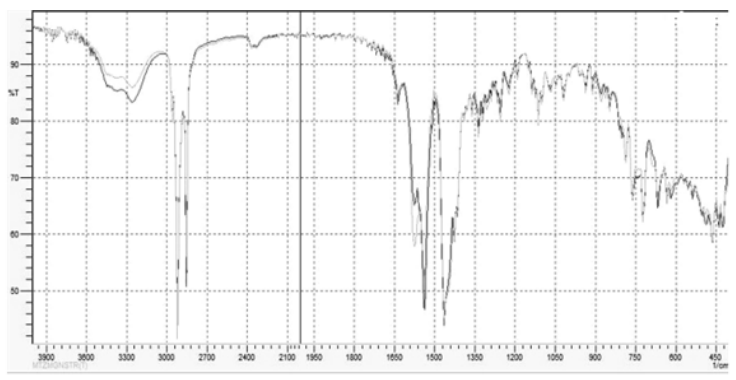

(H)

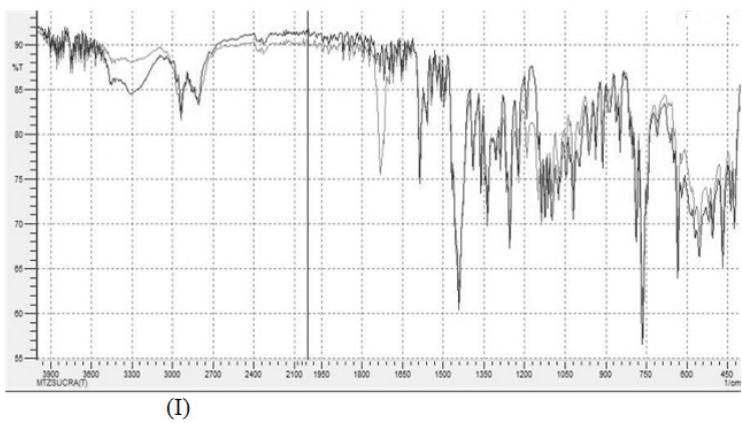

Figure 3.8 FTIR Spectra of (a) Mirtazapine USP; (b) Test and Control sample of Mirtazapine-Eudragit EPO granules; (c) test and control sample containing Crospovidone; (d) Test and Control sample containing Physically mixed Eudragit EPO; (e) test and control sample Containing Talc; (f) test and control sample containing Orange Flavor; (g) test and control sample containing MCCP 200; (h) test and control sample containing Magnesium stearate; (i) test and control sample containing sucralose.

\section{Conclusion}

From the present study, it can be concluded that the unpalatable taste of mirtazapine can be masked using Eudragit EPO polymer by mass extrusion technique. The drug-polymer ratio $1: 2$ is optimum for masking the bitter taste of mirtazapine. The result of the present study showed that wetting time and In-vitro disintegration time followed the order $\mathrm{SSG}>\mathrm{CCS}>\mathrm{CPV}$. Among all the formulations, formulation F9 containing crospovidone in $5 \%$ of total tablet weight showed the least disintegration time of $13.6 \pm 2.70$ seconds, wetting time of $18.13 \pm 0.24$ seconds, and maximum cumulative percentage drug release of $101.32 \pm 1.54 \%$ in SGF. The percentage drug release of this formulation in SSF was found below $10 \%$ even at the end of 5 minutes. Thus, it can be concluded that the unpalatable taste of mirtazapine can be masked by mass extrusion technique using Eudragit EPO, and the addition of superdisintegrants is a promising approach to prepare orally disintegrating tablets of Mirtazapine.

\section{Ethics approval and consent to participate}

Informed consent from the volunteers was obtained after informing them precisely about the purpose of the study. Verbal consent was 
obtained as the volunteers were used for the taste recognition purpose only and the research involved no more than the minimal risk to the subject.

\section{Consent for publication}

Not applicable.

\section{Acknowledgments}

The authors are grateful to Simca Laboratories Pvt. Ltd, Byasi, Bhaktapur, Nepal for their kindness to provide space, materials, and instruments to conduct this study. The authors also like to acknowledge Evonik Industries Pvt. Ltd, Mumbai for providing the gift sample of Eudragit EPO.

\section{Authors' contributions}

P.S. carried out the experiment. P.S. wrote the manuscript with support from R.S. and S.S. The project was supervised by R.S. and S.S.

\section{Competing interests}

The authors declare that they have no known competing financial interests or personal relationships that could have appeared to influence the work reported in this paper.

\section{References}

1. Patel A, Amrit S. Formulation taste masking-from bitter to better: the latest taste masking techniques can yield more palatable drugs. Pharm Formul Qual. 2009. p. e2.

2. Sohi H, Sultana Y, Khar RK. Taste masking technologies in oral pharmaceuticals: recent developments and approaches. Drug development and industrial pharmacy. 2004;30(5):429-448.

3. Sharma S, Lewis S. Taste masking technologies: a review. International journal of pharmacy and pharmaceutical sciences. 2010;2(2):6-13.

4. Gosai AR, Patil SB, Sawant KK. Formulation and evaluation of orodispersible tablets of ondansetron hydrochloride by direct compression using superdisintegrants. Int J Pharm Sci Nanotechnol. 2008;26(1):106111.

5. Pandey P, Dahiya M. Oral disintegrating tablets: a review. International Journal of Pharma Research \& Review. 2016;5(1):50-62.

6. Konapure SA, Chaudhari PS, Oswal RJ, et al. Mouth dissolving tablets" an innovative technology. International Journal of applied biology and Pharmaceutical Technology. 2011;2(1):496-503.

7. Dhakane K, Rajebahadur M, Gorde P. A novel approach for taste masking techniques and evaluation in pharmaceutical: An updated review. Asian J Bio Pharm Sci. 2011;1:18-25.

8. Timmer CJ, Sitsen JA, Delbressine LP. Clinical pharmacokinetics of mirtazapine. Clinical pharmacokinetics. 2000;38(6):461-474.

9. Drugs.com. Mirtazapine. 2018.

10. Patra CN, Priya R, Swain S, et al. Pharmaceutical significance of Eudragit: A review. Future Journal of Pharmaceutical Sciences. 2017;3(1):33-45.

11. Moustafine R, Bukhovets A, Sitenkov A, et al. Eudragit E PO as a complementary material for designing oral drug delivery systems with controlled release properties: comparative evaluation of new interpolyelectrolyte complexes with countercharged eudragit L100 copolymers. Molecular pharmaceutics. 2013;10(7):2630-641.
12. Drašković M, Medarević D, Aleksić I, et al. In vitro and in vivo investigation of taste-masking effectiveness of Eudragit E PO as drug particle coating agent in orally disintegrating tablets. Drug development and industrial pharmacy. 2017;43(5):723-731.

13. Veeraveni R, Kamaeswara Rao C, Shreedhar Nampalli GKY, et al. Design and evaluation of orodispersible taste masked valdecoxib tablets. Journal of Chemical and Pharmaceutical Research. 2011;3(4):882-892.

14. Patil MG, Kakade SM, Pathade SG. Formulation and evaluation of orally disintegrating tablet containing tramadol hydrochloride by mass extrusion technique. Journal of Applied Pharmaceutical Science. 2011;1(6):178.

15. Haware RV, Chaudhari P, Parakh S, et al. Development of a melting tablet containing promethazine $\mathrm{HCl}$ against motion sickness. Aaps Pharmscitech. 2008;9(3):1006-1015.

16. Kulkarni AP, Khedkar AB, Lahotib SR, et al. Development of oral disintegrating tablet of rizatriptan benzoate with inhibited bitter taste. $\mathrm{Am}$ J Sci Res. 2012;7(3):47-57.

17. Randale SA, Dabhi CS, Tekade AR, et al. Rapidly disintegrating tablets containing taste masked metoclopramide hydrochloride prepared by extrusion-precipitation method. Chemical and Pharmaceutical Bulletin. 2010;58(4):443-448.

18. $\mathrm{Hu} \mathrm{X}, \mathrm{Li} \mathrm{Y}$, Zhang E, et al. Preparation and evaluation of orally disintegrating tablets containing taste-masked microcapsules of berberine hydrochloride. Aaps Pharmscitech. 2013;14(1):29-37.

19. Ratnaparkhi Mukesh P, Jagadale Sachin K, Patil Pradeep S, et al. Formulation Development and Evaluation of taste masked orally disintegrating tablets of Perindopril Erbumine by direct Compression method. Int J Drug Dev Res. 2012;4:374-394.

20. Kulkarni L, Metkari V, Bamane G, et al. Recent trends on achieving taste masking of bitter drug. Current Pharma Research. 2014;4(3):1246.

21. Tan Q, Zhang L, Liu G, et al. Novel taste-masked orally disintegrating tablets for a highly soluble drug with an extremely bitter taste: design rationale and evaluation. Drug development and industrial pharmacy. 2013;39(9):1364-1371.

22. Khan S, Kataria P, Nakhat P, et al. Taste masking of ondansetron hydrochloride by polymer carrier system and formulation of rapiddisintegrating tablets. AAPS pharmscitech. 2007;8(2):E127-E33.

23. Zade PS, Kawtikwar PS, Sakarkar DM. Formulation, evaluation and optimization of fast dissolving tablet containing tizanidine hydrochloride. Int J Pharm Tech Res. 2009;1(1):34-42.

24. Alghabban FM, AL Ani IH, Hassan SF. Taste masking of prifinium bromide in orodispersible tablets. Int J Pharm Pharm Sci. 2014;1:315319.

25. Jadon RS, Nayak S, Amlan S, et al. Taste masking of Lornoxicam by polymer carrier system and formulation of oral disintegrating tablets. International Journal of Drug Delivery. 2009;1(1):1.

26. Rajitha K, Shravan KY, Adukondalu D, et al. Formulation and evaluation of orally disintegrating tablets of buspirone. Int J Pharm Sci Nanotechnol. 2009;1(4):327-334.

27. Hiremath S, Makanapur C. Formulation and evaluation of orodispersible tablets of a model anti-hypertensive drug. Int J Pharm Pharm Sci. 2017;9:34-38.

28. Chandira RM, Venkataeswarlu B, Kumudhavalli M, et al. Formulation and evaluation of mouth dissolving tablets of the etoricoxib. PakJ Pharm Sci. 2010;23(2):178-181. 